\title{
Authentic Materials - A Natural Resource for Developing Academic English
}

\author{
Jana Bére-ová*
}

Faculty of Education, Trnava University Hornopotočná 23, Trnava 918 43, Slovakia

Corresponding Author: Jana Bére-ová, E-mail: jana.beresova@truni.sk

\section{ARTICLE INFO}

Article history

Received: April 11, 2018

Accepted: July 06, 2018

Published: October 31, 2018

Volume: 9 Issue: 5

Advance access: August 2018

Conflicts of interest: None

Funding: None

Key words:

Authentic materials,

Critical thinking,

Effective argumentation,

Academic writing

\begin{abstract}
The approach to language learning as a way of coming to understand target culture and its impact on target language is reflected in the concept of teaching and learning languages through the integration of intercultural capabilities. The concept will be supported by a number of examples taken from authentic materials language learners have encountered in target language contexts, predominantly gaining experience through reading authentic materials. The paper presents the ideas of university students who carried out their own projects within and after research run by Trnava University, the representatives of which actively participated in a three-year project, supported by the VEGA funding scheme under number 1/0106/15. Twenty-two students who participated in our experiment were asked to analyze formal English in its written mode, searching for characteristic features of formal writing, used in contemporary English. After the completion of the first task related to the selection of appropriate samples, the students were expected to compare the quality of authentic materials received through technologies and that achieved from reading contemporary literary prose, newspapers and academic texts. The idea behind this task was to help university students to be able to critically assess other people's ideas and arguments, to apply critical thinking when reading, to evaluate authentic materials and to achieve the ability to construct effective arguments in formal writing.
\end{abstract}

\section{INTRODUCTION}

Languages are intertwined with the culture of their native users and as they influence each other, the intertwinement between them is clearly recognizable in the utterances produced by native speakers. Despite the fact that the focus of traditional language teaching was put on native-likeness and good language learners were expected to use native-like pronunciation and master grammatical patterns with proper use of vocabulary, many foreign language users were able to use the acquired language more theoretically rather than practically. It is possible to sort out a list of pitfalls the language learners encountered in traditional teaching. One of them was an intensive correction of their utterances that prevented them from speaking fluently, spontaneously and naturally. Summing up the list of pitfalls can be provided through generalization that the emphasis on accurate language prevailed over its natural use for real-life purposes when language users apply communicative language skills in their integration.

Bachelor and master degree studies are officially completed by theses submission and their oral defense. In a variety of tertiary education institutions, the requirements differ in particulars. However, it is possible to generalize the main distinctions. While bachelor-degree students can still focus on the study of a particular topic, master-degree students are obliged to implement practical research with intent to present their findings, justifying their opinions and conclusions, and providing evidence that concerns their research. Both pieces of writing entail unique approaches of thesis writers, nevertheless, universities usually provide their students with a handbook containing clear guidance on aspects of thesis writing. The handbook will normally clarify the maximum length of theses, thesis format, main areas to be covered, etc. The thesis format is often elaborated into details such as text type and size, line spacing, style of referencing, apart from clear instructions referring to thesis structure and so on. Students are expected to show that they are competent researchers, which seems to be a very difficult task for them as this is predominantly the first time they have attempted such a piece of work of this magnitude working independently, though supervised by their supervisors. Therefore, most universities have special academic courses during which students are provided with information concerning particular stages they have to follow, for example, putting forward research proposal, evaluating literature pertinent to their research objectives, using a variety of sources, designing methods for data collection, implementing empirical research, analyzing and discussing findings, drawing conclusions, summarizing recommendations with the final stage that concerns wrapping up research work.

However, these requirements refer to writing a thesis in the mother tongue and do not concern the skills necessary to write a coherent, accurate and logical text in a target lan- 
guage. Writing a thesis in English requires from students to be able to summarize information from sources written in both native and target languages, reconstruct arguments and accounts in a coherent presentation of the overall result and write a clear, well-structured text in an appropriate and effective style, using natural, accurate and appropriate English. This task is challenging and demands university students to master the language in order to analyze the information they gain from a variety of sources as well as to be able to use the academic tone of theses, proper for writing in English. For non-native speakers, writing a thesis in English should be intensively practiced to help students develop specific writing and analytic skills, for example, how to develop a logical sequence of ideas or to write effective paragraphs. Therefore, courses called English for Academic Purposes are incorporated into university study programs all over the world.

\section{METHODOLOGY}

In Slovakia, students who major English encounter a number of problems as they are obliged to write their theses in English. Despite the fact that they have spent many years learning English (at least seven years at primary school and four years at secondary school), majority of them is able to use English at level B2 of the Common European Framework of Reference (CEFR) in their first year of bachelor-degree studies. Taking part in many academic courses related to linguistic disciplines, reading literary works of famous British and American writers, they head for $\mathrm{C} 1$, predominantly in communicative language skills. Learning a target language does not narrow the focus of learning to the linguistic dimension. It entails the intercultural dimension as well to enable language learners to realize that linguistic formulae are the surface indicators of native speakers' cultural knowledge. In writing, there are certain conventions non-native students might not be aware of and should be presented, for example, genre-based writing (Jordan, 2012).

In our research conducted in 2015-2017, we could discover that only $45 \%$ of students were aware of culturally-induced language and of how culture affects the way of expressing ideas and opinions. Regardless the fact, the national curricula for primary and secondary schools entail the intercultural dimension, only few teachers devote their classes to these issues. It is also due to the fact that officially this part of the curriculum content is obligatory and serves as a stimulus for teachers what they should do in their English class. The purpose of these words is not to emphasize the fact that learners studying English at primary and secondary schools should be given lectures related to the interaction between cultural thought patterns and rhetorical patterns, yet we reject the idea that teaching writing in English is based on the mother tongue models and previous experience related to writing in the mother tongue. Writing in Slovak is significantly different from writing in English from the cultural perspective, for example, communication in Slovak is direct with a different rhetoric style of constructing utterances. In addition to this, Slovak native speakers quite often express their viewpoints without any justification and critical thinking is not developed properly at primary and secondary ed- ucation institutions, despite the intensive debate in society that it should be focused on at any level of education.

Writing theses in English should be preceded by training students to think critically, construct sentences logically, write proper topic sentences, present the line of reasoning, provide evidence to illustrate someone's argument and avoid overgeneralization, irrelevance, etc. English major students need to be trained to understand concepts concerning critical thinking. For students, who have never written a longer piece of writing, there are weighty pressures associated with initiating the process and usually do not feel self-confident enough to start without being supervised. It is recommended to start with writing academic essays because they include research (Chin, Reid, Wray \& Yamazaki, 2013). However, the thesis viewed as a detailed discourse on a subject is more than an extended essay. Students are obliged to submit an independent piece of work to satisfy a board of examiners that they are competent to do research and present their advanced knowledge on a specific topic, which requires a systematic approach and intensive work.

In our research, the first step was to support developing students' strategies associated with critical thinking such as attention, categorization, selection, and judgements. Twenty two students who decided to participate in our experiment were explained a concept of critical thinking viewed as identifying positive as well as negative aspects of a particular issue, and that to be able to critique refers to being able to acknowledge that there are several ways of looking at any issue, and sometimes they might be quite distinct from each other. This approach was fundamental as the students were expected to encounter authentic materials to develop their intercultural communicative competence which concerns the abilities to communicate effectively and appropriately in a target cultural context. Writing their theses, students are expected to employ a variety of sophisticated language and to communicative complex ideas in an effective way. To be able to do it, they need to analyze a number of texts to discover salient characteristics of a written text in English. The students participating in our experiment were provided with a set of materials, selected on purpose, which entailed two chapters or articles, each taken from a variety of sources: applied linguistics, British newspapers and contemporary literary prose. Since young people prefer working with information technologies, they were required to analyze two pieces of writing presented online. Information technologies provide contemporary information and this contemporaneity means that technology-mediated information does not exist simply as static information. Real-world instantiations of attitudes, values, and understandings offer opportunities for reflection. Students analyzed BBC topical news and discuss the issues, but considered the language used in the mass media difficult. Apart from using printed dictionaries and grammar reference books, the students were instructed to get as much information as possible concerning particular structures used currently in English through searching for their frequency on the Internet.

\section{THE FINDINGS}

Apart from the focus on language (morphology, syntax, lexicology and stylistics) used in the articles, students (22) 
engaged in our research were expected to discover the pragmatic and socio-linguistic aspects of using English by native speakers. The idea behind this requirement was based on the descriptors provided in the CEFR Companion Volume Provided with New Descriptors (2017) that reads for a C1 level of sociolinguistic appropriateness: Can adjust his/her level of formality (register and style) to suit the social context: formal, informal or colloquial as appropriate and maintain a consistent spoken register. Can frame critical remarks or express strong disagreement diplomatically (Council of Europe, 2017:137) and for thematic development entailed in pragmatic competence: Can use the conventions of the type of text concerned to hold the target reader's attention and communicate complex ideas. Can give elaborate descriptions and narratives, integrating sub themes, developing particular points and rounding off with an appropriate conclusion. Can write a suitable introduction and conclusion to a long, complex text. Can expand and support main points at some length with subsidiary points, reasons and relevant examples (Council of Europe, 2017: 140).

During the experiment, students focused on samples of English that attracted their attention and initiated an intense discussion in working groups. They verified the use, frequency and appropriateness of chosen samples on the Internet and compared them with possible Slovak translations. They realized that sentences are constructed and linked differently and came to a conclusion that they cannot translate their Slovak thinking into English while writing in English. They conceived an idea of a necessity to focus more on proficiency in English, either specialized or cultural knowledge to be able to express their ideas accurately and appropriately, respecting the style and the purpose of the text constructed in English. They became aware of formal writing that should be clear and objective and that their ideas must be expressed in a formal, factual way. From the linguistic point of view, they concluded some of the ways in which formal writing is different from informal forms of writing, such as avoidance of slang and informal language, use of complex sentences, avoidance of contractions, use of the passive, use of the nouns, etc.

Table 1 shows the most frequently selected samples of salient features students chose for discussion. While discussing salient features of formal writing in English, students focused on current trends in contemporary English as they were to read only materials published recently. Despite the fact that some of salient features are viewed as more formal than the others in a variety of grammar-reference books, students could find them in both formal and less formal modes. All the tendencies students were able to systemise were analysed and thoroughly discussed as some of them seemed to be more characteristic for particular genres. Those ones that are typical for academic writing such as hedging, boosting (Carter \& McCarthy, 2013) or using reporting verbs, language of description, classification and evaluation, etc. (Bérešová, 2014) were not discussed, despite the fact that some of them were recognized by students. The intention was to provide students with a number of samples that are characteristic for formal writing, and only later let them focus on academic writing, introducing other patterns in order not to overwhelm students with a large number of patterns at a time. The philosophy behind this was to encourage them to read anything in the original language to be exposed to English as much as possible.

\section{DISCUSSION}

Students were motivated to discover the ways of expressing ideas and opinions naturally, appropriately and accurately. They encountered authentic texts that were thoroughly chosen on purpose, with the aim to facilitate their communication in written mode. Their engagement in the task was supported by the fact that they are expected to write their theses in English, the task they have never encountered before and that is a big unknown for them. The task accomplishment was based on their own decision, either to work individually or in groups, in which they could discuss particular patterns and the effect of their mother tongue on their writing in English. Most of them changed the way of working; once they wanted to focus on collecting samples and needed silence to be able to concentrate on particular samples, another time they enjoyed sharing their samples and discussing whether they follow the instructions and focus on the same aspects. They cooperated intensively when drawing on their common conclusions about the relevant sampling.

The selection of the materials was aimed at making students read any authentic materials, despite the fact that academic books seemed to be the best choice. The original idea was aimed at discovering how much about discourse students can learn while reading contemporary literary prose, newspapers and online articles in case they represent a formal or less formal way of writing. Students were recommended that they should use formal language for writing theses while less formal language is acceptable when offending their theses. Accomplishing the first task, students were expected to write a paragraph and present it, focusing on the areas in which they could recognize interference of their mother tongue.

As writing is a complex process which demands cognitive analysis and linguistic synthesis, students could discover the differences in sentence constructions in both languages English and Slovak, based on a distribution of communicative dynamism where 'theme' describes the topic or starting point for a message and 'rheme' refers to the information about the theme. Since English word order is quite restricted or fixed, communicative dynamism is based on different rules of its distribution. Analyzing various sentences, students were able to become aware of expressing new ideas in English sentences and came to conclusions that sentences in their mother tongue have the rheme placed at the end, which is its standard position while in English the theme-rheme order is not kept rigidly also in cases nothing stood its way apparently. Although word order in an English sentence is fixed by the grammatical factor, students were able to find examples, in which they could recognize distribution of communicative dynamism from the highest to the lowest degree, for example, Thousands of federal employees [who had been placed on temporary, unpaid leave since Saturday] breathed a sigh of relief, in which thousands of federal employees is themat- 
Table 1. Formal English - salient features

\begin{tabular}{|c|c|}
\hline Salient features & Samples \\
\hline Comment relative clauses & $\begin{array}{l}\text { There is a naturalness with which they assimilate another language, once they are regularly exposed to } \\
\text { it, which is the envy of adults (Crystal, 2003: 17). } \\
\text { But the positive is that Guy Batchelor his handling his new role well, which is giving me a bit more time } \\
\text { to get on with all the pre-trial paperwork I have to deal with (James, 2017: 230). } \\
\text { The authorities have also put } 407 \text { people under house arrest since Nov. 14, requiring them to report to } \\
\text { the police three times daily, which forced those who were working to quit their jobs or take leaves of } \\
\text { absence (International New York Times, 2016: 5). }\end{array}$ \\
\hline Pragmatic markers & $\begin{array}{l}\text { The other points, however, need to be taken more slowly, to appreciate the alternative } \\
\text { perspectives (Crystal, 2003: 16). } \\
\text { In addition to the approving glances of the other guests, the woman in white held the full attention of } \\
\text { two sleek security officers who shadowed her closely (Brown, 2017: 61). } \\
\text { Throughout it all, the OED churns on, attempting to be slightly more complete today than it was } \\
\text { yesterday (The Guardian, 2018: 29). }\end{array}$ \\
\hline Punctuation rules & $\begin{array}{l}\text { One important aim of the current update, therefore, was to, finally, provide such descriptor scales for } \\
\text { mediation (Council of Europe, 2017: 47). } \\
\text { And the, out of the blue, three days ago, Langdon had received a FedEx envelope with a plane ticket, } \\
\text { a hotel reservation, and a handwritten note from Edmond urging him to attend tonight's event (Brown, } \\
\text { 2017: 14). } \\
\text { But in some eyes, not least the editor's, the book was also a heroic failure (The Guardian, 2018: 27) }\end{array}$ \\
\hline Nominalisation & $\begin{array}{l}\text { However, the emergence of any one language as global has only a limited causal relationship to this } \\
\text { unhappy state of affairs (Crystal, 2003: 21). } \\
\text { Kirsch gave a gracious smile and shook the man's hand (Brown, 2017: 9). } \\
\text { The quest to capture 'the meaning of everything'.... has absorbed generations of lexicographers } \\
\text { (The Guardian, 2018: 27). }\end{array}$ \\
\hline Impersonal style & $\begin{array}{l}\text { It remains to be seen whether such affirmations of good will have long-term effect (Crystal, 2003: 19). } \\
\text { After a career of giving commands, it was a relief to relinquish the helm and let others steer this } \\
\text { ship (Brown, 2017: 22). } \\
\text { It's hard to make that into a selling point for the technology (International New York Times, 2016:18). }\end{array}$ \\
\hline The passive & $\begin{array}{l}\text { As stated above, this ability can be viewed both as an interaction strategy or as an integral aspect of } \\
\text { discourse competence (Council of Europe, 2017: 96). } \\
\text { They would know more about Kipp Brown when he was questioned (James, 2017: 234). } \\
\text { Words that would previously been spoken are now typed on social media (The Guardian, 2018: 28). }\end{array}$ \\
\hline Existentials & $\begin{array}{l}\text { There is no shortage of books - chiefly within the genre of science fiction - which foresee a future in } \\
\text { which, following some cataclysmic scenario, the universal language is Chinese, Arabic, or even some } \\
\text { Alien tongue (Crystal, 2003: 26). } \\
\text { There was a gap between a white van and a little Hyundai (James, 2017: 237). } \\
\text { There is little evidence that the modern electorate wants to embrace the heavy-metal socialism of a } \\
\text { super-statist society (the Guardian, 2018:18). }\end{array}$ \\
\hline Inversion & $\begin{array}{l}\text { Never has the need for more widespread bilingualism been greater, to ease the burden placed on the } \\
\text { professional few (Crystal, 2003:14). } \\
\text { The more he thought about Sandy's strange message, the less concerned he was (James, 2017: 225). } \\
\text { But a healthy and successful society shouldn't be sending this many overgrown children scurrying back } \\
\text { for refuge, nor should it leave quite this many parents feeling bad about it (The Guardian, 2018: 48). } \\
\text { No sooner have you reached the summit of the mountain than it has expanded another hundred feet (The } \\
\text { Guardian, 2018: 27). }\end{array}$ \\
\hline Cleft sentences & $\begin{array}{l}\text { What has been so impressive about the developments which have taken place since the } 1950 \text { s is that } \\
\text { they have affected to a greater or lesser extent, every country in the world, and that so many countries } \\
\text { have come to be involved (Crystal, 2003: 13/14). } \\
\text { 'What you are about to see,' Kirsch said, 'is a rough cut of an announcement I hope to share with the } \\
\text { world - perhaps in a month or so' (Brown, 2017: 10). } \\
\text { 'What I am interested in is a good bit of fun' (The Guardian, 2018: 23). }\end{array}$ \\
\hline
\end{tabular}

ic and conveys the lowest degree of communicative dynamism while breathed a sigh of relief is rhematic due to the highest degree of communicative dynamism, referring to the main part of the message, which indicates the important information about the topic. It might be also presented that a completely new message was achieved through the verb breathed as transition. Some students preferred breaking down a communicative field into communicative units when communicative fields were larger than one clause or sentence and an analysis of sentence elements was based on larger communicative units, for example, Republican Senate leader Mitch McConnell said his part had come to an arrangement 
(theme) to negotiate on the Democrats' calls for an immigration deal (rheme). They were recommended to focus on these issues more intensively in their translation and interpreting courses. Academic writing requires constructing sentences in a target language. However, using sources written in their mother tongue demands certain skills of mediating the information from one language into another.

Despite the fact that university students are exposed to reading materials related to their academic courses, they mainly focus on slow reading during which they try to understand the subject of the topic or to get as much content as possible, without paying a particular attention to specific issues such as distribution of communicative dynamism or the ways of a natural flow of ideas in a particular context. Students could become aware of different patterns of textual organisation and the fact that inadequate or inconsistent application of writing strategies in English above word level may lead to instances of incoherence at the level of discourse. The students managed to reveal a significance of topic sentences that introduce paragraphs, enabling writers to develop a paragraph by justifying their viewpoints.

\section{IMPLICATIONS AND SUGGESTIONS}

Language learning is influenced by several factors, out of which one seems to play a significant role - being exposed to language as much as possible. Therefore, English major students were provided with a short list of newspaper articles and book chapters they were to read, focusing on contemporary English. The aim of the activity was based on our previous experience concerning language competence of university graduates which is usually more theoretical rather than practical and most students were struggling with different problems in writing in English. To complete their degrees at both levels of university education, either bachelor's or master's, students are obliged to produce a long text in which they analyse, synthesise, compare or contrast - a text that needs to be written in natural, appropriate and accurate English. This is viewed as a very demanding task as most English major students have never experienced writing such a complex text in English.

In general, it seems to be important to present students with samples of good practice that enable them to discover how the sentences are constructed, and ideas worded, formulated and linked to one cohesive and coherent text. Since there are differences between writing in Slovak and English, students need to segment sentence elements to see how the language works properly in case they want to express their viewpoints clearly and comprehensively. Despite the fact that academic writing in different languages has some common features such as impersonal style, there are other issues Slovak students are not familiar with and have to focus on while writing in English, for example, the passive, pragmatic markers, punctuation rules, nominal tendencies, etc.

The experiment twenty-two students participated in proved our assumption concerning the concept of learning through doing as the participants were able to discover current tendencies in contemporary English and typical features of writing in a target language. Based on our teaching experience, it is possible to conclude that when Slovak learners write in Slovak, their sentences are less-focussed and vaguer, and emotional factors are more prevalent in the decision making while writing in English makes Slovak learners to be more rational and logical, accepting the style native speakers formulate their sentences in. This cultural aspect seems to be important to be taken into account while teaching writing in a target language as it might result in making students use a target language effectively. This should be supported by exposing language learners to authentic materials, either printed or online. Despite the fact that they prefer working with online materials, during the experiment, students admitted that it had been easier for them to work with printed materials as they could write their comments and underline the sentences chosen for a thorough analysis. The only drawback referring to printed materials was their availability any time students decided to work on them. The quality of language both sources provided students with was considered high as the texts were purposefully chosen and written in Standard English.

Working with the materials was based on several stages, the cycle of which was not straightforward linear, therefore students needed to be aware of possible revisiting previous stages, a necessity to search for additional materials or consulting dictionaries and grammar-reference books for information on particular issues, omitting irrelevant information that do not relate to the chosen structures and patterns, problem solving through more thorough analysis of collected data, etc. While analyzing and discussing the collected data, students frequently compared practical research findings with information achieved from literature review. Since these are general stages of writing any academic paper or thesis, regardless of the university degree students intend to achieve, students were given opportunities to experience a process of doing research with the aim to develop their writing skills.

\section{REFERENCES}

Bérešová, J. (2014). English for Academic Purposes. Trnava: Pedagogická fakulta Trnavskej univerzity.

BBC. (2017). US shutdown ends as Congress passes bill. Available on: http://www.bbc.com/news

Brown, D. (2017). Origin. UK: Penguin, Random House.

Carter, R. \& McCarthy, M. (2013). Cambridge Grammar of English. Cambridge: Cambridge University Press.

Council of Europe. (2001). Common European Framework of Reference for Languages: Learning, teaching, assessment. Cambridge: Cambridge University Press. Council of Europe. (2017). CEFR Companion Volume With New Descriptors. Strasbourg: Council of Europe, Education Policy Division.

Crystal, D. (2003). English as a Global Language. Cambridge: Cambridge University Press.

Guardian News and Media. (2018). The Guardian. Vol. 198, No 15, pp. 18-29.

New York Times Company. (2016). The International New York Times. Thursday, February 18, 2016.

James, P. (2017). Need You Dead. London: Macmillan.

Jordan, R. R. (2012). English for Academic Purposes. Cambridge: Cambridge University Press. 